\title{
Assessment of Some Medical Malpractice Cases During Surgical Procedures in Yemen
}

\author{
Nabil H. S. AL Hamady \\ Assistant professor, Department of Forensic Medicine and Clinical Toxicology \\ Faculty of Medicine and Health Sciences, Sana'a University.
}

\begin{abstract}
Aim of work :- This research aims to study some cases of medical malpractice and provides guidance for medical persons to minimize or even avoid medical malpractice among Yemenis.

Subjects and Methods:- This first study in Yemen was done on hundred cases of medical malpractice during surgery that were collected randomly through the last ten years (1996-2005) from many places in Yemen. All cases were aging from 3 to 70 years old. The gender of patient was 54 males and 46 females.

Results:-This study showed highly significant increase of number of cases between ages 21- 30, 41- 50 and 51-60 in both sexes as compared to other groups of age, while ages 11-20 and 31-40 showed significant increase in number of malpractice cases versus age 61-70 years. No significant difference between females and males among the studied cases. There was very highly statistical significant increase of number of malpractices that done by one physician when compared to that done by two or three physicians. There was very highly significant increase in number of malpractice cases in public hospital versus other hospitals and in private hospitals versus academic hospitals. Positive cases of medical malpractice were very highly significantly decreased as compared to negative one in public and private hospitals \& no significant difference between positive and negative cases in academic hospitals. There was very highly significant increase in number of malpractice cases among specialists as compare to university staff and consultant. There was no statistical significant difference between university staff and consultants. There was also very highly significant increase in number of negative cases among university staff and specialists, but significant increase of negative cases as compared to positive cases was seen among consultants. This study proved that the general surgery showed very highly significant increase in number of malpractice cases versus other groups. Urology showed significant increase in number of malpractice cases versus internal medicine and neurosurgery. It was demonstrated very highly significant increase in number of malpractice cases during intra-operative and post-operative stages versus other stages. Appendicectomy and cholecystectomy showed very highly significant increase in number of malpractice cases versus other types of operations. There was no statistical significant difference between the distribution of criminal and civil cases among the studied cases. A statistical significant difference was shown between the final outcome in number of deaths and complete recovery when compared with cases of permanent deformity.
\end{abstract}

\section{Introduction and Aim of Work}

When a physician accepts patient for diagnosis and treatment both of them acquired legal rights and obligations. These rights and obligations affect every aspect of the physician patient relationship, for example, choice of drugs, diagnostic investigations, medical procedures and use of medical equipments, (Angela and Holder, 1974).

Once a physician - patient relationship has been established the physician has a duty to provide a level of care similar to other physicians of the same field of practice. If the patient sufferd compensable 
injury due to breech of the standard of care, suit may succeed (Edward, 2002).

The word "negligence" has a special meaning it is defined as the omission to do something which a reasonable man would not do. It could be defined as failure to perform the duty to exercise a reasonable degree of skill and care in the treatment of patient (Parik,1996).

Malpractice of abdominal and pelvic surgeries were very common because they contain many systems and structures as GIT, urinary system, genital system as well as main blood vessels and nerves. Therefore the possibility of complications increased like missing surgical dressing, instruments or injuries of important structure during operations ( Knight, 1996).

This research aim to study some cases of medical malpractice and pro-vides guidance for medical persons to mini-mize or even avoid medical malpractice among Yemenies.

\section{Subjects and Methods}

\section{(A) Subjects}

This presented study was done on 100 random cases of medical malpractice collected from Yemen through the last ten years (1996-2005). All cases were collected from the archives of some public and private hospitals, or the archives of bureau of the medicolegal department, Ministry of Justice through the last ten years . Also some cases of medical malpractice were confronted to me to give my own opinion were also collected in this study .All cases were aging from 3 years old up to 70 years old. The gender of patients was classified into 54 males and 46 females.

\section{(B) Methods :}

This study comprised many data which were reflected from the randomly collected medical malpractice cases through the last ten years(1996-2005). All these data were tabulated, graphed and statistically analyzed with special reference in some cases to positive( the physician was guilty) and negative (the physician was not guilty) claims. The relation between age and sex among the medical malpractice cases, that collected randomly was studied .

The number of physicians who were involved in the offered medical service where studied and tabulated in relation to the number of malpractice. The places of the offered medical services may be public hospitals, private hospitals, private clinics and academic hospitals. These places were categorized and tabulated to be studied.

The number of cases of malpractice as regard the degree of qualification (academic staff, consultant or specialist) were listed and analysed statistically. The number of malpractice cases concerning the branches of medical specificity among the random collected samples, for example : general surgery, internal medicine, neurosurgery obestetric and urology. The exact stage, at which the alleged malpractice was took place, could be one of the following according to (Aly, 2005) : Preoperative, Intra-operative, Post-operative and Medical or therapeutic stages.

The relation between the type of operations (medical procedure) and the type of medical malpractice was also studied.

Medical malpractice cases in this study were of two types either criminal or civil.

The final results or prognosis presented in this study were graded into :

1. Death of the patient: the medical service or procedure terminated by death.

2. Permanent infirmity : the medical service offered to the patient leads to permanent infirmity.

3. Recovery : the medical service offered to the patient was followed by complete recovery of the patient.

Statistical analysis was performed using Chi-sqare test and $\mathrm{Z}$ test (Sendecor, 1981).

\section{The Results and Discussion}

All data were analyzed statistically \& the results were illustrated in tables and figures as follows:

Table (1) and figure (2) illustrated highly significant increase of the total 
number of cases between ages 21-30, 41-50 and 51-60 years in both sexes as compared to other groups of age. However ages 11-20 and 31-40 years showed significant increase of number of cases of malpractice versus age 61-70 years. There was no significant difference between females and males among studied group (Fig.1) .

Faysal. and Omar (2004) said that there was no special institute or organization that receive claims of malpractice in Egypt. Moreover there was no specialized groups or board to discuss and analyse these claims. This was in agreement with our results as the same problems are presented in Yemen .

Table (2) and figure (3) showed that there was a very high statistical significant increase in the medical malpractice cases done by one physician when compared to that done by two or three physicians ( $\mathrm{p}<$ 0.001 ). On the other hand, there was no statistical significant difference in the percentage of the malpractice cases produced by two or three physicians ( $p>$ $0.05)$.

Harvard (1990) stated that in New York hospitals, in 1986, commission of medical malpractice is relatively rare . It was found that hospital malpractice incidence was 3.7 percent. However this percentage of adverse events due to physician team was 1 percent.

Therefore presence of more than one physician was important to help each other and decrease the possibilities of errors. When a physician failed to perform duties of standard care and injury or damage to the recipients of these services occurred, claims of malpractice raised (Dubay et al.,2001).

Table (3) and figure (4) demonstrated that there was very highly significant increase in number of malpractice cases in public hospitals versus other places while showed very highly significant increase of number of malpractice cases in private hospitals and private clinic versus academic hospitals.

Table (4) showed very highly significant decrease in number of positive cases as compared to number of negative cases in public and private hospitals. There was significant decrease in positive cases as compared to negative cases in private clinic, while no significant difference between positive and negative cases in academic hospitals.

This was in agreement with Inwald, et al. (2001) and Anderson, (2000) who reported that hospitals are responsible for any mistakes or negligence done by doctor, nurse or other health care professional who works in a hospital e.g errors in drug administration, wrong dosage, wrong medications, wrong site of surgery, wrong patient, wrong surgical procedure and leaving surgical instruments in patients' body.

Dubay et al. (1993) reported that claims for negligent medical treatment have escalated greatly in recent years; the worst situation being in hospitals of North America. The patient might bring a legal suit against hospital or doctor or anyone who works there in some countries; the hospital or government are responsible for the negligence of employed doctors.

There is a common legal principle in all aspects of employment that " the master is responsible for the acts of his servants ". This is applied equally to hospital authorities.

For comparison a study was done by Harvard medical school; who found that , over $5 \%$ of all hospital patients were injured as a result of medical malpractice, (Randell, 2001).

Harvard (1990) found that $1 \%$ of representative sample of patients treated in New York state hospitals in 1984 were injured and one quarter of those patients died because of medical negligence. The board of professional medical conduct (1999) estimated that 98000 patients may be killed each year in hospitals of United States alone as a result of medical errors.

Table (5) and figure (5) showed that there was very highly significant increase in the distribution of malpractice cases among specialists when compared to those produced by both University Staff and Consultants $(p<0.001)$. On the other hand, there was no statistical significant difference between University Staff and Consultants ( $p>0.05$ ). 
As regard the number of negative and positive cases in each degree of qualifiction (table 6 and fig. 6) showed very highly significant increase in number of negative cases as compared to positive cases among university staff and specialists. Significant increase of negative cases as compared to positive cases was seen among consultants.

Knight (1996) explained that the duty of medical professional usually is not the duty to cure or to guarantee a good outcome from treatment instead his duty is to provide medical care according to the accepted medical standards in his specialty.

Forgarty (2003) proved that the medical record was the only source, other than memory, to tell what has occurred with a patient. It was the key for successful defence. A poorly documented medical record implies similar quality of medical care. This opinion explained the presented results, where the university staff learned and trained to record every thing about his patient in a systemic order indicating his skillful medical care. Also the specialists took strict care and offered all available efforts of medical care to avoid faults. Therefore there was very highly significant increase in number of negative cases "physicians are not guilty" as compared to positive cases "physicians are guilty".

Table (7) and figure (7) proved that the general surgery showed a very highly significant increase in number of malprctice cases versus other groups. Urology showed significant increased in number of malpractice versus internal medicine and neurosurgery.

These results were in agreement with Knight (2004) who reported that the autopsy on post-operative deaths revealed that most common malpractice sequeleae occurred with abdominal and thoracic procedures. The so called anaesthetic deaths may be minimal or even absent .

Knight (1997) mentioned that the range of medical errors and negligence leading to injury are broad. The different medical specialties have greatly different risks and it is impossible to give complete list of them.
Table (8) and figure (8) demonstrated very highly significant increase in number of malpractice cases during intra-operative and post-operative stages versus other stages while showed highly significant increase of number of malpractice in no malpractice cases versus diagnostic; preoperative and therapeutic stages among the random collected samples.

Omar (2005) stated that postoperatively the anesthetist should confirm regaining all protective reflexes of the patient and assure haeomodynamic stability till the patient become fully conscious.

Other postoperaive examples of malpractice reported by ( Knight and Pekka, 2004) were negligence of the resuscitation protocols e.g giving anticoagulant drugs to patients with head injuries when there was associated cardiac disease as this might be complicated by development of serious cerebral hemorrhage with coma and death.

Table (9) and figure (9) recorded that appendicectomy and cholecystectomy showed very highly significant increased in number of malpractice versus other types of operation.

Knight (1996) and Faysal and Omar (2004) reported that in the field of general surgery, medical malpractice occurred most commonly with cholecystectomy operations. The second most common cause of medical malpractice were following appendisectomy.

Table (10) and figure (10) showed that there was no statistical significant diffrence between the distribution of criminal and civil cases among the studied groups.

Parik (1996) reported that civil negligence suits arise when patient or his relatives sued a doctor in a civil court for compansation for injury or death of patient due to negligence of the doctor. These civil suits might arise by the doctor against the patient or his relatives when they refused to pay the doctors fees. Smith (2001) reported that criminal negligence claims are raised in cases of serious injuries or death of patient. This might be due to wrong diagnosis, gross ignorance, gross careles-sness or 
neglect life and safety of the patient, leading to criminal charge against doctor. Examples of such negligence include :

- Injection of basal anesthetics in fatal dosage or in wrong tissues.

- Amputation of wrong limb, removal of wrong organ or erros in ligation of ducts.

- Operation on wrong patient

- Performing criminal abortion.

- Sexual misbehaviour with patient

Table (11) and figure (11) showed a statistical significant difference between the final outcome in number of cases ended by death or by complete recovery when compared with cases of permanent deformity.

Harvard (1990) and journal of American Medical Association (J.A.M.A) reported that over 225.000 people died each year due to iatrogenic cause. They also reported that

1) 12.000 deaths occurred from unnecessary surgery per year.

2) 7.000 .000 deaths per year from error medication in hospital .

3) 20.000 deaths per year from other errors in hospitals.

4) 80.000 deaths per year form infection in hospitals

5) 106.000 deaths per year from non. error adverse effects of medication.

\section{Recommendations}

(1) Continuous medical education of licensed accredited personnel, about standards of care protocols for patient safety and about medicolegal ethics.

(2) Regulatory disceplinary reactions should be enforced towards non. accredited places or personnel.
(3) Physicians should obtain a written and informed consent, where all the major complications of the planned medical procedure were adequately explained to the patient.

(4) Any hospital should record all therapeutic procedures, all observations about the patients conditions in the report, and keep a photography or copy of the written report in Arabic and English languages.

(5) The laboratories should be well equipped and provided by qualified personals.

(6) Complete and full laboratory investigations should be done before any surgical procedure even minor operation.

(7) The medical reports in any hospital should be written by qualified medicolegal experts on a special form designed for medicolegal purposes. These forms should be signed by the name of the physician and his job, the name of the medicolegal expert and the signature of the general manager of the hospital.

(8) Establishment of an organization in all hospitals to receive and verify any malpractice claims. This organization consists of :

$>$ Members from the medical syndicate.

$>$ Medicolegal experts.

$>$ Lawyers persons.

$>$ Specialists of forensic Medicine from university staff.

(9) Every physician should respect his specialty and his degree so as not to interfere with his colleagues in other specialties to avoid malpractice offenses. 
Table 1: The relation between age and gender distribution among random medical malpractice cases through the last ten years.

\begin{tabular}{|l||c||c||c|c|}
\hline Age & Female & Males & Total [n (\%)] & P value \\
\hline \hline $0-10 \mathrm{yrs}$ & 4 & 1 & 5 & $\mathrm{p}>0.05$ \\
$11-20 \mathrm{yrs}$ & 4 & 6 & 10 & $\mathrm{p}<0.05^{*}$ \\
$21-30 \mathrm{yrs}$ & 12 & 9 & 21 & $\mathrm{P}<0.01^{* *}$ \\
$31-40 \mathrm{yrs}$ & 6 & 7 & 13 & $\mathrm{P}<0.05^{*}$ \\
$41-50 \mathrm{yrs}$ & 11 & 11 & 22 & $\mathrm{P}<0.01^{* *}$ \\
$51-60 \mathrm{yrs}$ & 7 & 19 & 26 & $\mathrm{P}<0.01^{* *}$ \\
$61-70 \mathrm{yrs}$ & 1 & 2 & 3 & $\mathrm{p}>0.05$ \\
Total & $45(45 \%)$ & $55(55 \%)$ & 100 & $\mathrm{P}>0.05$ \\
\hline
\end{tabular}

$\mathrm{P}>0.05=$ Not significant. ${ }^{*} \mathrm{P}<0.05=$ significant. ${ }^{*} * \mathrm{P}<0.01=$ Highly significant.

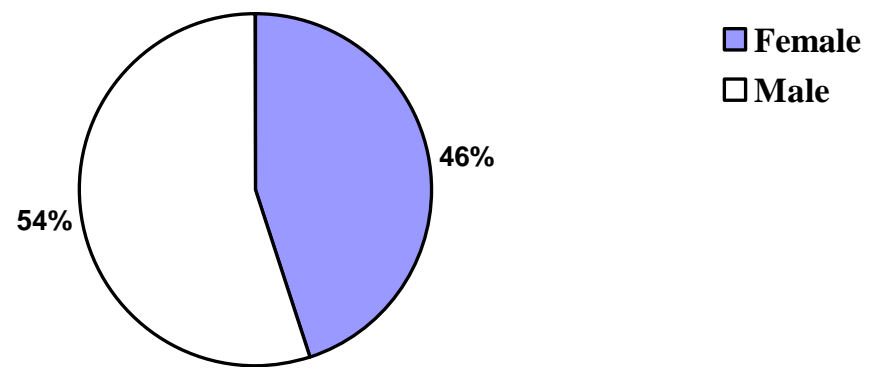

Fig. 1: Gender distribution among the random collected medical malpractice cases through the last ten years .

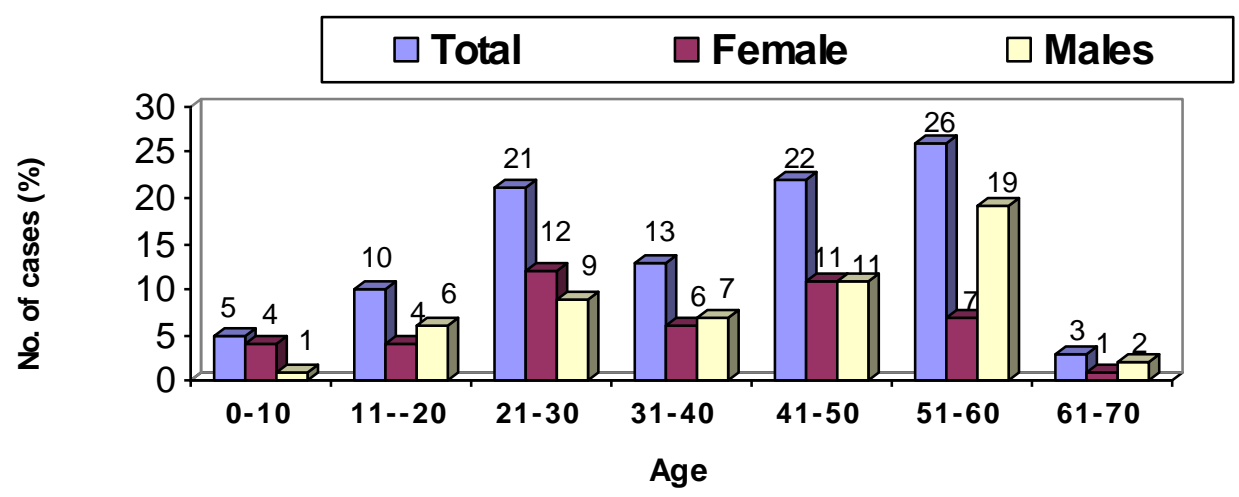

p $>0.05=$ Not significant $<0.001=$ very highly significant .

Fig. 2: Comparing the age of significance in relation to gender distribution among the random medical malpractice collected cases through the last ten years.

Table 2: Number of physicians in relation to number of collected malpractice cases through the last ten years.

\begin{tabular}{|l||c||c||}
\hline No. of physician & No. of malpractice cases [n (\%)] & P value \\
\hline \hline One physician & $92(92 \%)$ & $\mathrm{p}<0.001^{* * *}$ \\
Two physicians & $6(6 \%)$ & $\mathrm{P}>0.05$ \\
Three physicians & $2(2 \%)$ & $\mathrm{P}>0.05$ \\
\hline
\end{tabular}

$\mathrm{P}>0.05=$ Not significant. $\mathrm{P}<0.001=$ very highly significant. 
Nabil H. S. AL Hamady

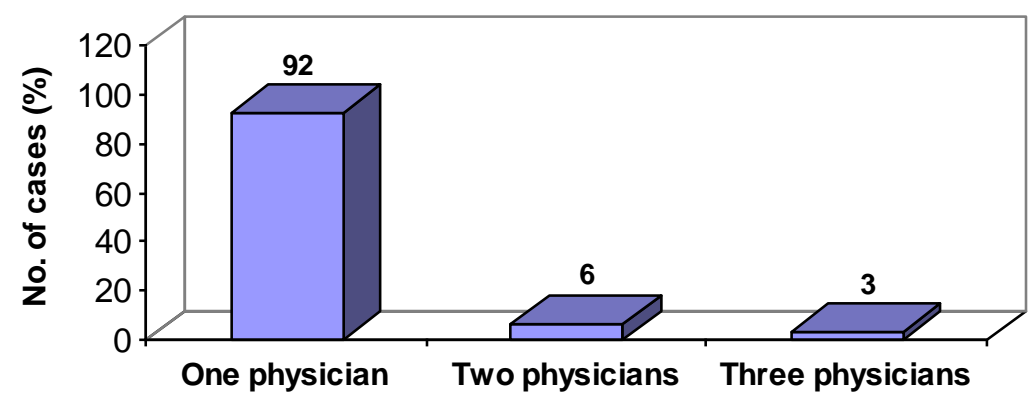

Fig. 3: Number of physicians in relation to number of collected malpractice cases through the last ten years .

Table 3: Classification of random malpractice collected cases according to the place of offered medical services .

\begin{tabular}{|l||c||c|}
\hline \multicolumn{1}{|c||}{ Location of medical services } & No. of cases (\%) & \multicolumn{1}{c|}{ P value } \\
\hline \hline Public hospitals & $51(51 \%)$ & $\mathrm{P}<0.001^{* * *}$ \\
Private hospitals & $26(26 \%)$ & $\mathrm{P}<0.001^{* * *}$ \\
Private clinics & $21(21 \%)$ & $\mathrm{P}<0.001^{* * *}$ \\
Academic hospitals & $2(2 \%)$ & $\mathrm{P}>0.05$ \\
\hline
\end{tabular}

Table 4: Classification of random malpractice collected cases according to the negative and positive cases in each place of offered medical services .

\begin{tabular}{|l||c|c|c||}
\hline \multicolumn{1}{|c||}{ Location of medical services } & No. of negative cases (\%) & No. of positive cases (\%) & P value \\
\hline Public hospitals & $37(72.5 \%)$ & $14(27.5)$ & $\mathrm{P}<0.001^{* * *}$ \\
\hline Private hospitals & $21(80.8 \%)$ & $4(19.2 \%)$ & $\mathrm{P}<0.001^{* * *}$ \\
\hline Private clinics & $13(61.9 \%)$ & $8(38.1)$ & $\mathrm{P}<0.05^{*}$ \\
\hline Academic hospitals & $1(50 \%)$ & $1(50 \%)$ & $\mathrm{P}>0.05$ \\
\hline
\end{tabular}

$\mathrm{P}>0.05=$ Not significant. $* \mathrm{P}<0.05$ Significant; $* * * \mathrm{P}<0.001$ Very highly significant 


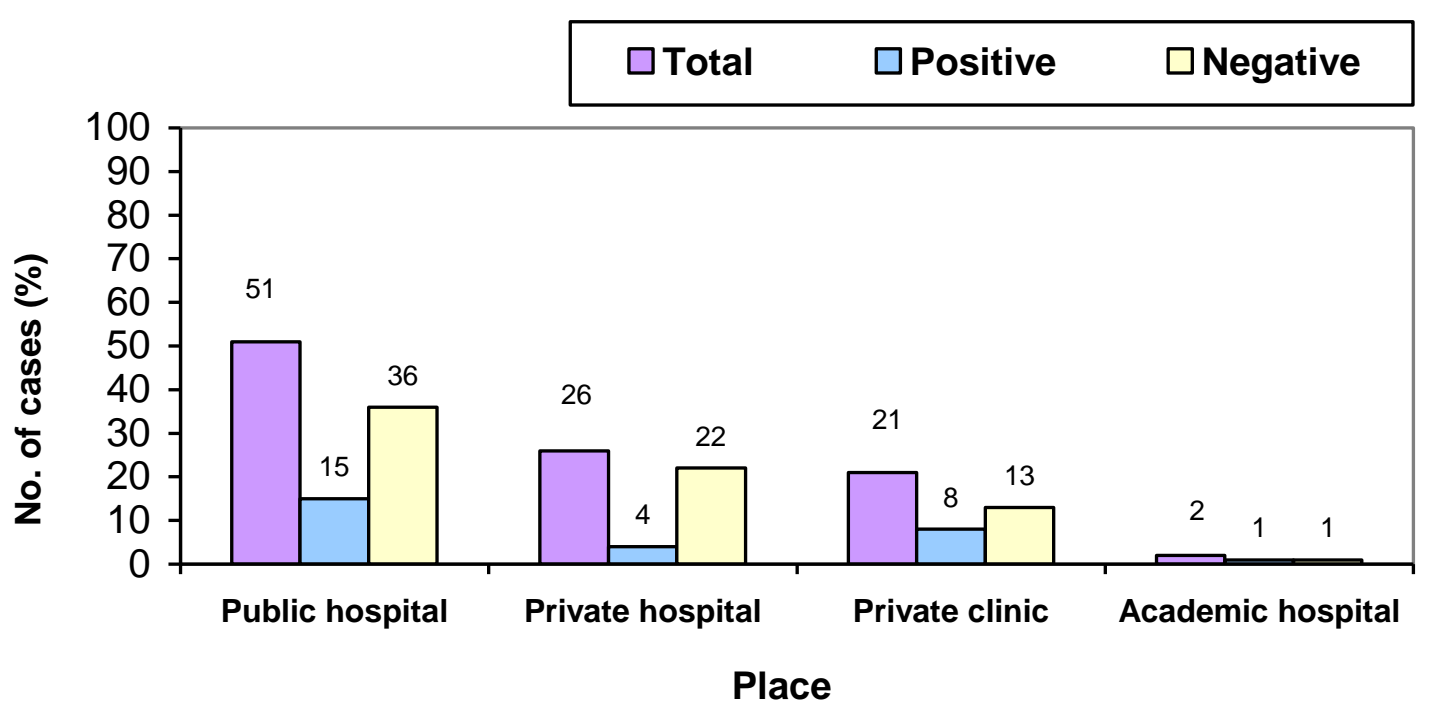

Fig. 4: Classification of random malpractice collected cases according to the place of offered medical services.

Table 5: Number of medical malpractice cases as regards the degree of medical qualification [n (\%)] among the random collected cases.

\begin{tabular}{|l|c|c|}
\hline Degree of qualification & No. of cases (\%) & P value \\
\hline \hline University Staff & $10(10 \%)$ & $\mathrm{P}>0.05$ \\
Consultant & $17(17 \%)$ & $\mathrm{P}>0.05$ \\
Specialist & $73(73 \%)$ & $\mathrm{P}<0.001 * * *$ \\
\hline
\end{tabular}

$\mathrm{P}>0.05=$ Not significant. $* \mathrm{P}<0.001=$ Very highly significant

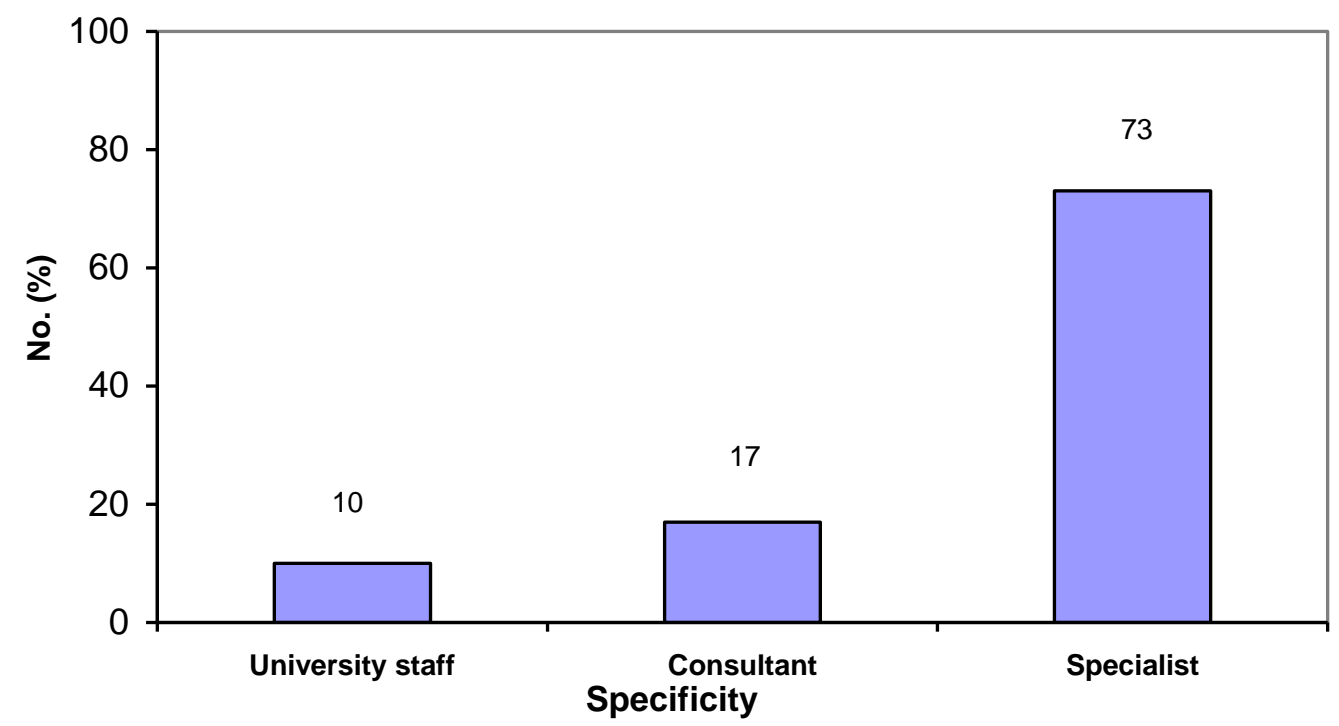

Fig. 5: Number of malpractice cases as regard the degree of qualification [n (\%)] among the random collected cases. 
Table 6: Number of malpractice cases as regards the negative and positive cases in each degree of qualification [n (\%)] among the random collected cases.

\begin{tabular}{|c|c|c|c|}
\hline Degree of qualification & No. of negative cases (\%) & No. of positive cases $(\%)$ & $\mathrm{P}$ value \\
\hline $\begin{array}{l}\text { University Staff } \\
\text { Consultant } \\
\text { Specialist }\end{array}$ & $\begin{array}{c}10(10 \%) \\
11(64.7 \%) \\
51(69.9 \%)\end{array}$ & $\begin{array}{c}0(0 \%) \\
6(35.3 \%) \\
22(30.1 \%)\end{array}$ & $\begin{array}{c}\mathrm{P}<0.001 * * * \\
\mathrm{P}<0.05 * \\
\mathrm{P}<0.001 * * *\end{array}$ \\
\hline
\end{tabular}

$\mathrm{P}>0.05=$ Not significant $* \mathrm{P}<0.05$ Significant; $* * * \mathrm{P}<0.001$ Very highly significant

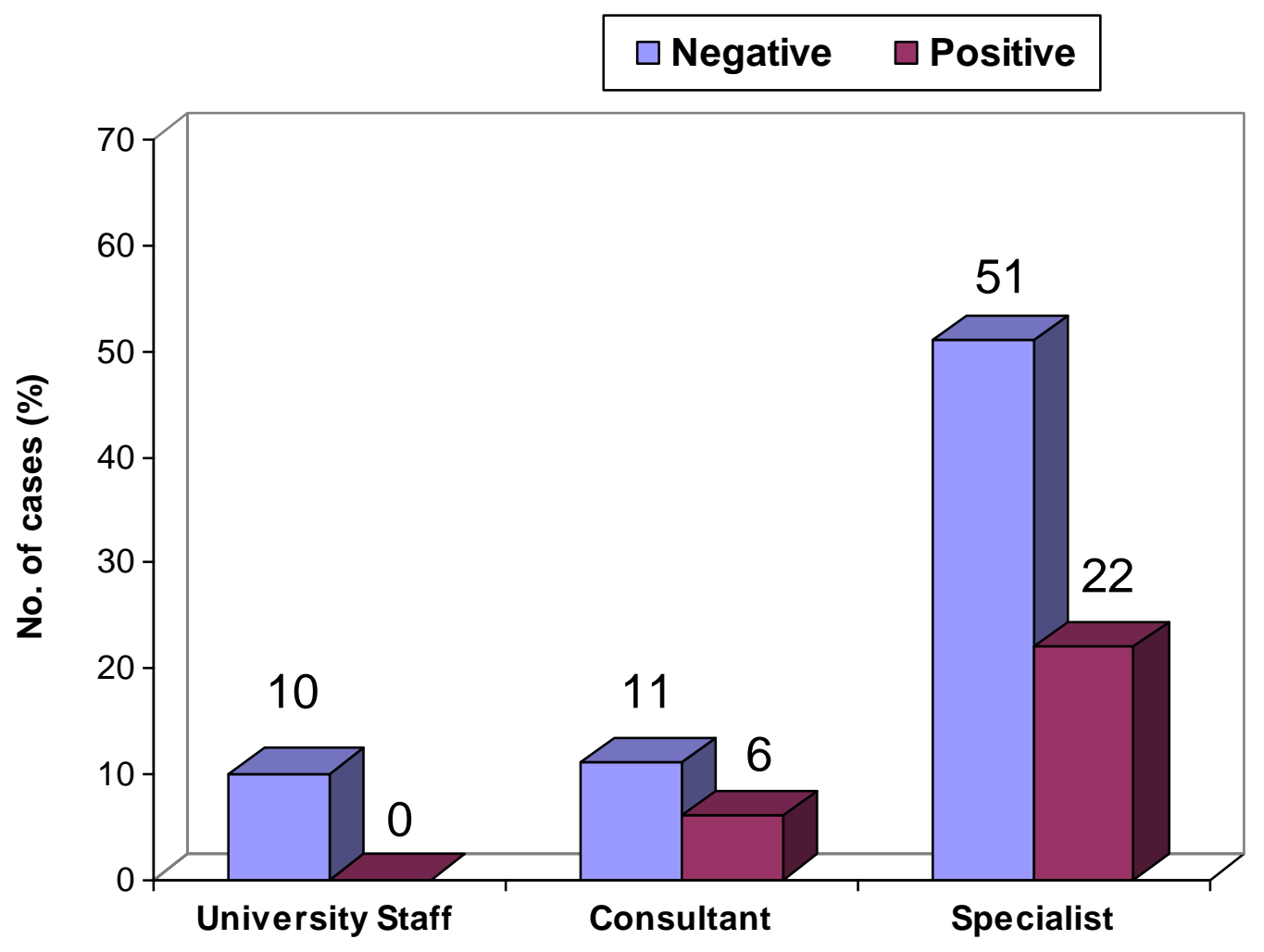

Fig. 6: Number of malpractice cases as regards the negative and positive cases in each degree of qualification [n (\%)] among the random collected cases.

Table 7: Number of malpractice cases concerning the branch of medical specificity [n (\%)] among the random collected samples.

\begin{tabular}{|c|c|c|}
\hline Branch of specificity & No. of cases $(\%)$ & $P$ value \\
\hline $\begin{array}{l}\text { General surgery } \\
\text { Internal medicine } \\
\text { Neurosurgery } \\
\text { Obstetric } \\
\text { Urology }\end{array}$ & $\begin{array}{c}82(82 \%) \\
1(1 \%) \\
3(3 \%) \\
5(5 \%) \\
9(9 \%)\end{array}$ & $\begin{array}{c}\mathrm{P}<0.001 * * * \\
\mathrm{P}>0.05 \\
\mathrm{P}>0.05 \\
\mathrm{P}>0.05 \\
\mathrm{P}<0.05^{*}\end{array}$ \\
\hline
\end{tabular}

$* * * \mathrm{P}<0.001=$ Very highly significant $\mathrm{P}>0.05=$ Not significant. $* \mathrm{P}<0.05=$ Significant 


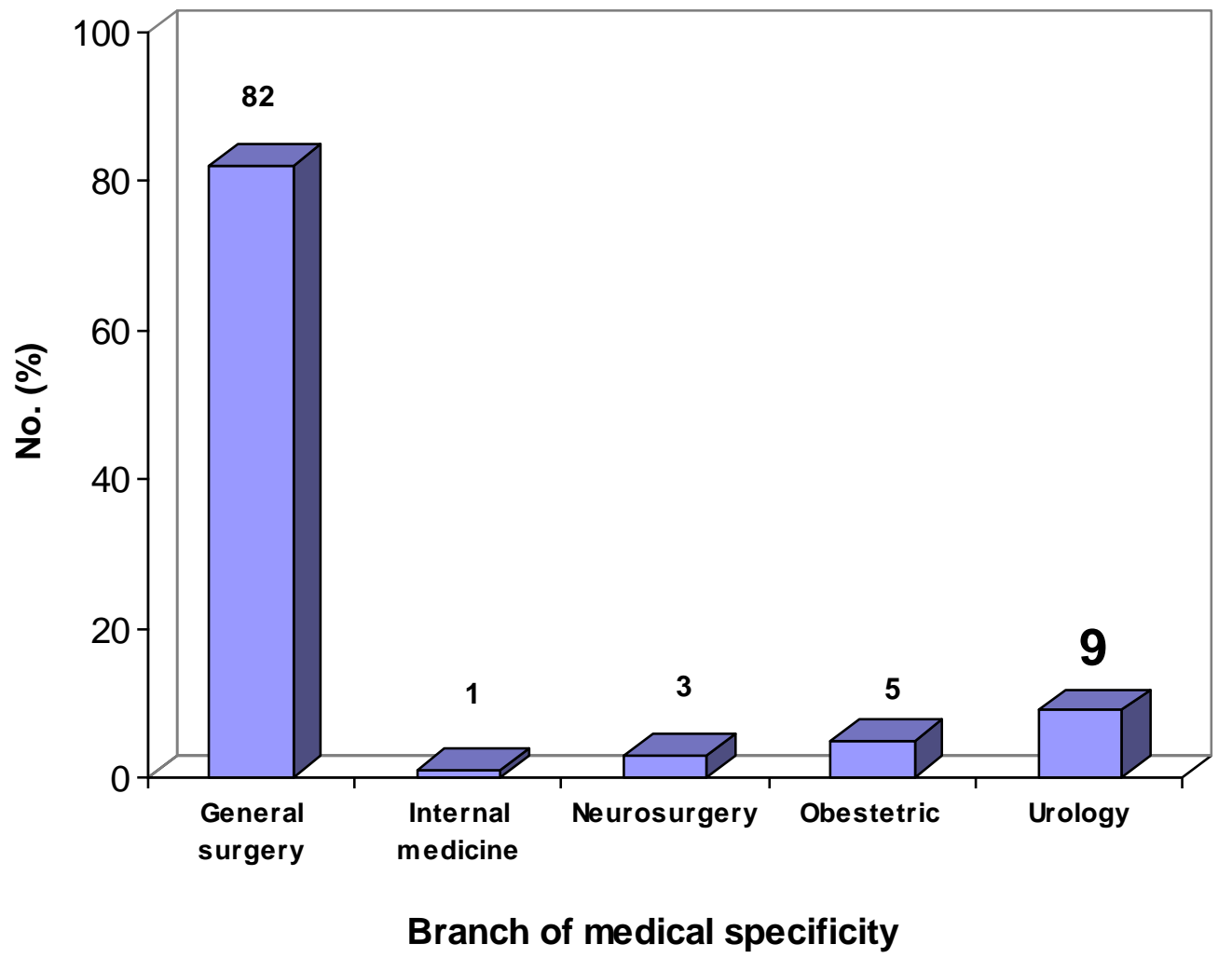

Fig. 7: Number of malpractice cases in relation to the type of medical specificity [n (\%)] among the random collected samples.

Table 8: Number of malpractice cases in relation to the stage of its occurrence [n (\%)] among the random collected cases.

\begin{tabular}{||l||l|l|}
\hline Stage of occurrence of malpractice & No. of cases $\mathbf{( \% )}$ & P value \\
\hline \hline Diagnostic stage & $2(2 \%)$ & $\mathrm{P}>0.05$ \\
Preoperative stage & $1(1 \%)$ & $\mathrm{P}>0.05$ \\
Intra operative stage & $40(40 \%)$ & $\mathrm{P}<0.001^{* * *}$ \\
Post operative stage & $42(42 \%)$ & $\mathrm{P}<0.001 * * *$ \\
Therapeutic stage & $1(1 \%)$ & $\mathrm{P}>0.05$ \\
No malpractice stage & $14(14 \%)$ & $\mathrm{P}<0.01 * *$ \\
\hline
\end{tabular}

$\mathrm{P}>0.05=$ Not significant. $\mathrm{P}<0.001=$ very highly significant. $\mathrm{P}<0.01=$ Highly significant. 
Nabil H. S. AL Hamady

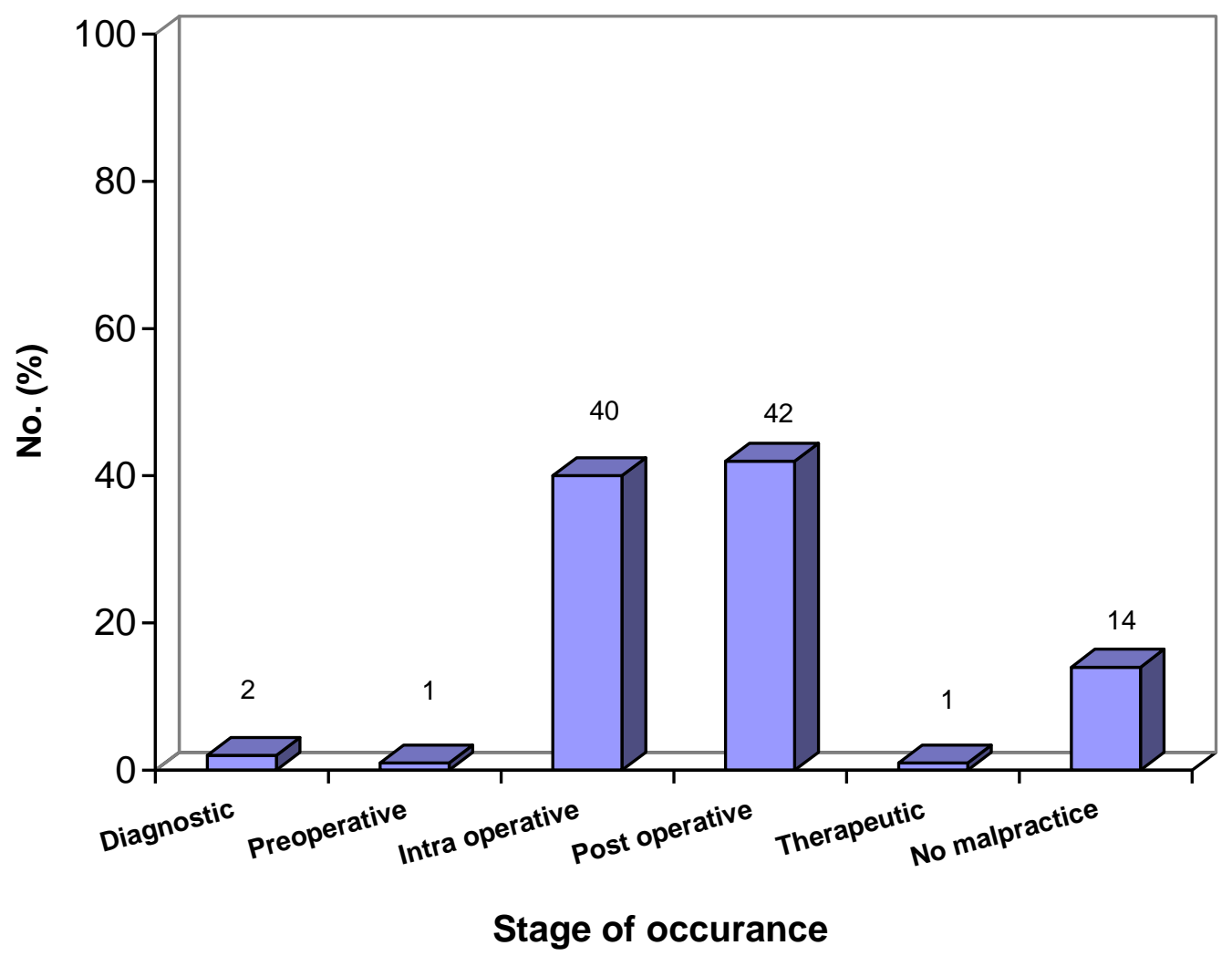

Fig. 8: Presented the number of malpractice cases in relation to the stage of its occurrence [n (\%)] among the random collected cases.

Table 9: Relation between type of operation and type of medical malpractice which may occurred among the random collected cases.

\begin{tabular}{|c|c|c|c|c|c|c|c|}
\hline \multirow[b]{2}{*}{ Medical procedure } & \multicolumn{5}{|c|}{ Operation care } & \multirow[t]{2}{*}{ Total } & \multirow[t]{2}{*}{ P value } \\
\hline & $\begin{array}{c}\text { Anesth. } \\
\text { complication }\end{array}$ & $\begin{array}{c}\text { Misinjection in } \\
\text { an artery }\end{array}$ & $\begin{array}{c}\text { Missed foreign } \\
\text { body }\end{array}$ & $\begin{array}{c}\text { Tear of a } \\
\text { viscera }\end{array}$ & $\begin{array}{c}\text { Other } \\
\text { complications }\end{array}$ & & \\
\hline Appendicectomy & 2 & & 6 & 8 & 15 & 31 & $\mathrm{P}<0.001 * * *$ \\
\hline Cholecystectomy & 3 & & 3 & 13 & 11 & 30 & $\mathrm{P}<0.001 * * *$ \\
\hline Laminectomy & & & & 1 & 2 & 3 & $P>0.05$ \\
\hline Obestetric surgery & & & 2 & 2 & 1 & 5 & $P>0.05$ \\
\hline Partial gastriectomy & & & & & 2 & 2 & $\mathrm{P}>0.05$ \\
\hline Repair of herniae & 1 & & & 2 & 6 & 9 & $\mathrm{P}<0.05^{*}$ \\
\hline Resction-anastomosis & 1 & & & & 3 & 4 & $P>0.05$ \\
\hline Splenectomy & & & & & 2 & 2 & $P>0.05$ \\
\hline Uretrolithiotomy & 1 & & & 1 & 7 & 9 & $\mathrm{P}<0.05^{*}$ \\
\hline Miscellaneous & & 1 & & 1 & 3 & 5 & P> 0.05 \\
\hline Total & 8 & 1 & 11 & 28 & 52 & 100 & \\
\hline
\end{tabular}

$\mathrm{P}>0.05=$ Not significant. $\mathrm{P}<0.001=$ very highly significant. $\mathrm{P}<0.05=$ significant. 


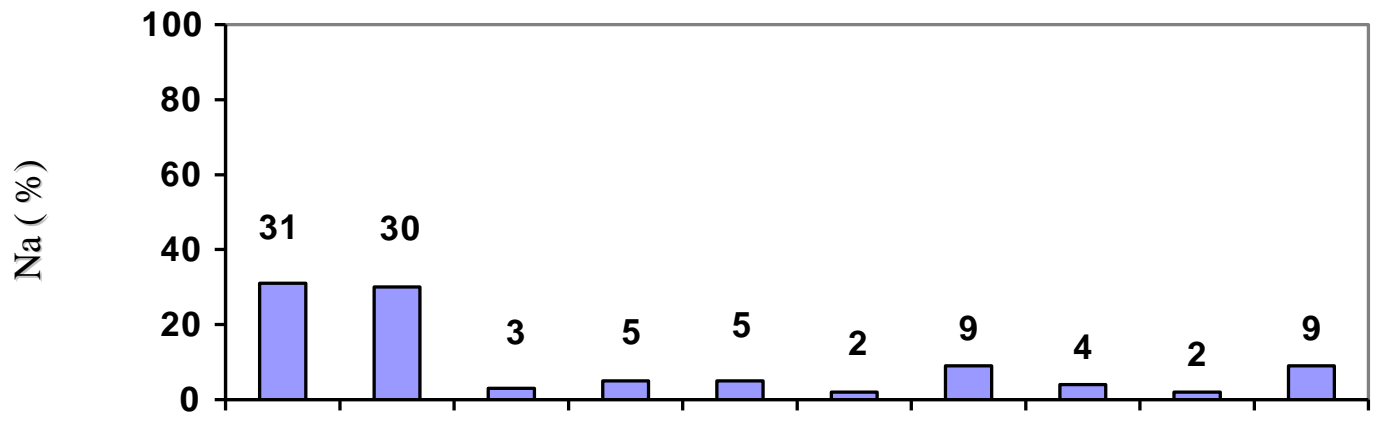

Appendicectomy Laminectomy obestetric surgery
Repair of herniae splenectomy

\section{Medical procedure}

Fig. 9: Relation between type of operation and type of medical malpractice which may occurred among the random collected cases.

Table 10: Type of raised claims regarding criminal or civil of the random collected cases.

\begin{tabular}{|l||c|c|}
\hline Type of raised claims & No. of cases $(\boldsymbol{\%})$ & P value \\
\hline Criminal & $51(51 \%)$ & \\
\hline Civil & $49(49 \%)$ & $\mathrm{P}>0.05$ \\
\hline
\end{tabular}

P> $0.05=$ Not significant.

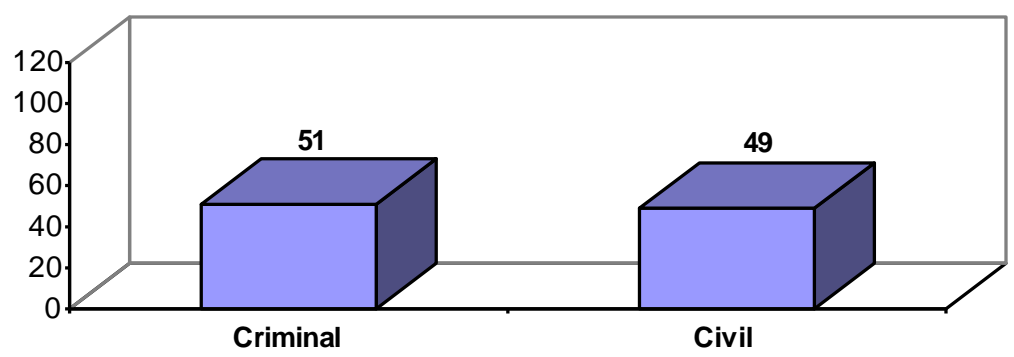

Fig. 10: The type of raised claims regarding criminal or civil of the random collected cases .

Table 11: Final outcome (Fate) of malpractice cases (percent) that collected randomly (2000-2004).

\begin{tabular}{|l||c|c|}
\hline Fate & No. of cases (\%) & P value \\
\hline \hline Death & $44(44 \%)$ & $<0.001^{* * *}$ \\
Permanent deformity & $7(7 \%)$ & $>0.05$ \\
Complete recovery & $49(49 \%)$ & $<0.001^{* * *}$ \\
\hline
\end{tabular}

$* * * \mathrm{P}<0.001=$ Very highly significant 


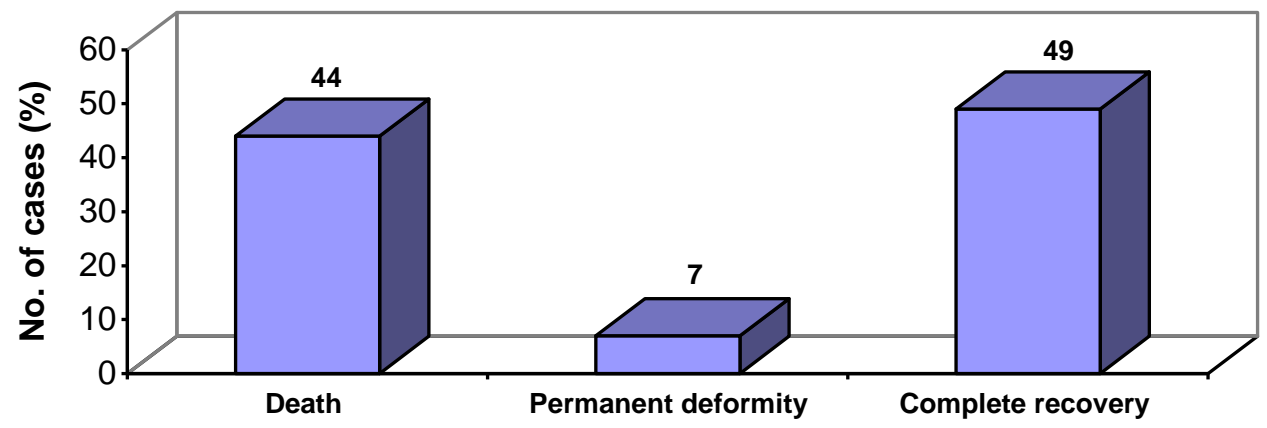

Fig. 11: Final outcome of malpractice cases (percent) that collected randomly.

\section{References}

1. Anderson CL (2000): Surgical operations and Law : Melbourne university Law Review 5 (1).

2. Angela $R$ and Holder JD (1974). Medical Malpractice Law.

3. Dubay MN, Sardoff LA, Malice AC (1993), a MANUAL Hilson Resea-rch Inc. new York, Journal of science and administration, 12 (1)

4. Dubay L, Kaestener $\mathbf{R}$ and Waim-ann T (2001). Medical malpractice Liab-ility and It's effection prenatal care utiliz-ation and infant health. Journal of health Economics. 20: 591-611

5. Edward E Bartlett (2002) . "computers can the wart "Medical malpractice claims" risk management pp.67-71.

6. Faysal, AK and Omar AH (2004): Medical Malpractice, thesis for M.D in Forensic Medicine and Toxicology, Faculty of Medicine Al-Minya University.

7. Fogarty CA (2003). Obstetrics and gynecology to be / or not to be? Factors influencing one decision department of obstetrics and gynecology, Creighton University medical center.

8. Harvard H (1990): Medical practice study patient doctors and lawyers : medical injury, malpractice litigation, and patient compensation in New York. Report of the Harvard medical practice study to the state of New York.
Cambridge, Mass, president and fellows of Harvard college.

9. Inwald $\mathbf{H} \mathbf{N}$, Woinasrki $\mathbf{J} \quad \mathbf{E}$ and Wright K R (2001): National conference on corrextional health care : eight national conference Canada 3: 36 .

10. Knight B (1996): " the doctor and the Law" In: medical Jurisprudence and Toxicology. Sixth edition. the law book compny (p) LTD. Allahabad-211001 ( India) pp. 77-78

11. Knight B (1997) : in Simpson Forensic Medicine, eleventh edition. London, New York Auckland. pp . 166,167.

12. Knight B and Pekka S (2004): Knight's Forensic pathology third edition. Deaths associated with surgical procedures.

13. Omar A H (2005) . Lectures of Forensic Medicine, medicolegal aspects of operative complications, 1-16.

14. Parik H S (1996). Text book of medical jurisprudence and toxicology, fifth edition.

15. Randell SB (2001) : “In mate rights reform in Sweden and Denmark" Journal of Criminal Law 63(2) : 240-255.

16. Sendecor, G.W. and Cochran , W.G. (1981). Statistical methods. $8^{\text {th }}$ edition, the Lowa State University press, Lowa, USA.

17. Smith F (2001): Personal communication May Joint commition on the accreditation of health care organization (JCAHO). 


\section{تقبيم لبعض حالات الأخطاء المهنية الطبية أثناء الإجراءات الجراحية في البين .

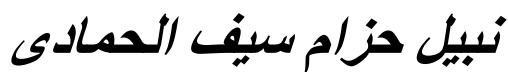 \\ قسم الطب الثر عي و السموم الإكلينيكية بكلية الطب و العلوم الصحية جامعة صناء}

هذه الدر اسة الفريدة والأولى في اليمن كانت قد أجريت على مائة حالة من حسالات الأخطاء المهنيـة

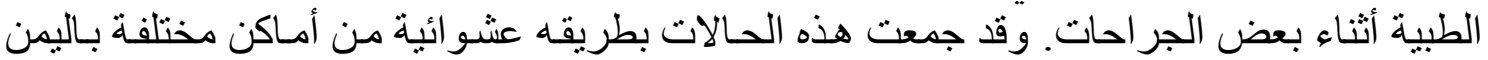

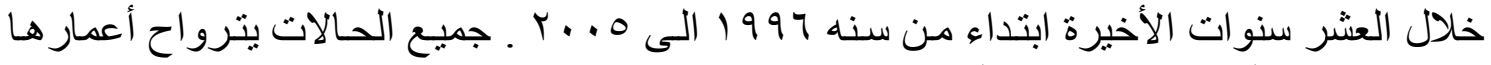

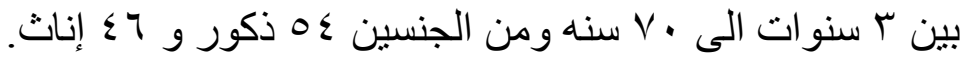

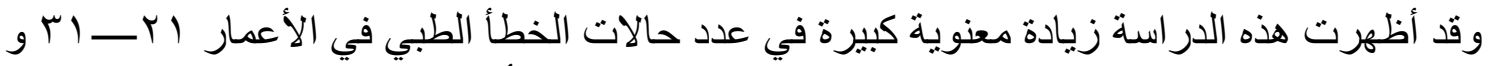

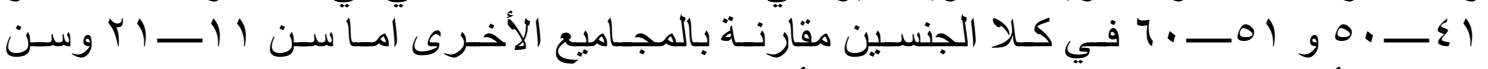

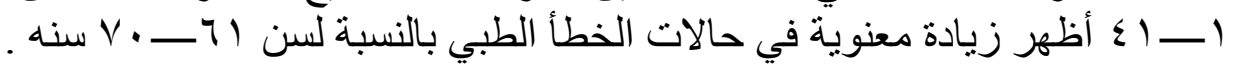

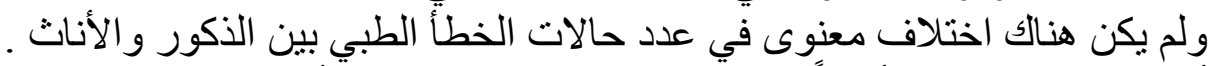

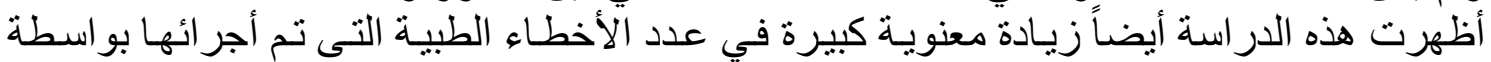

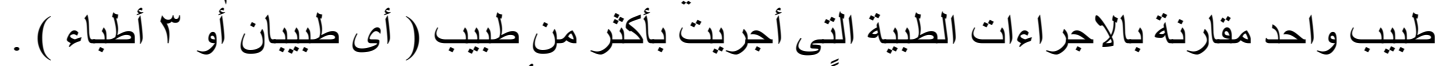

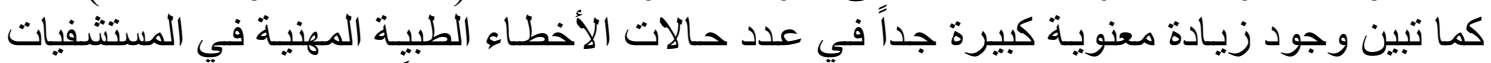

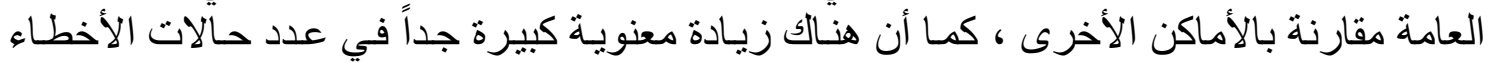

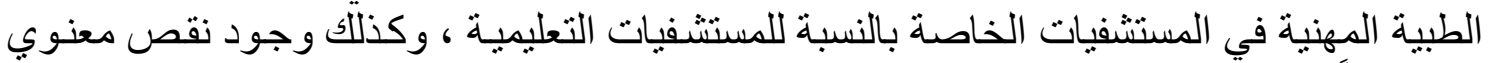

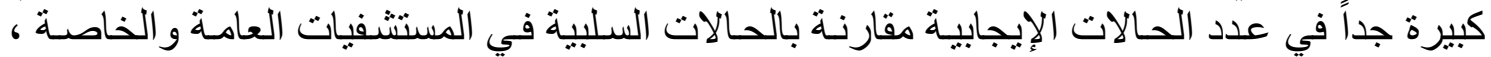

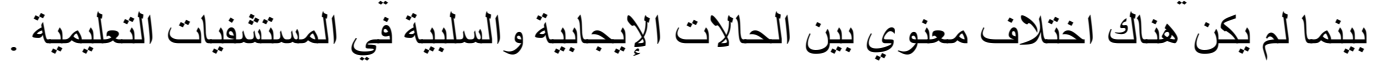

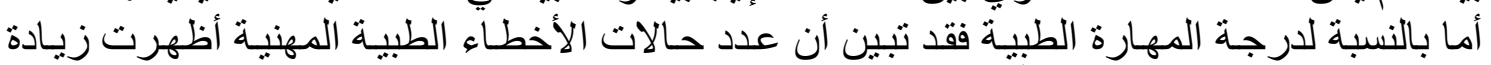

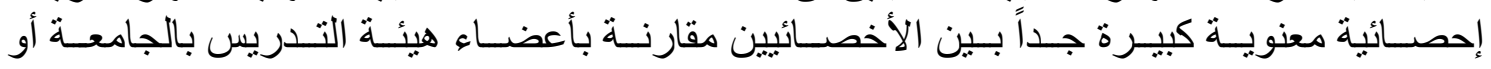
بالاستشاريين .

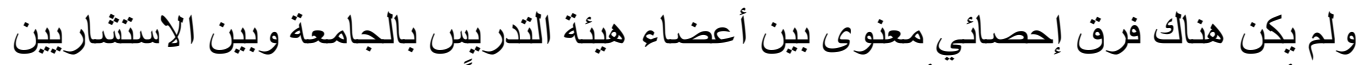

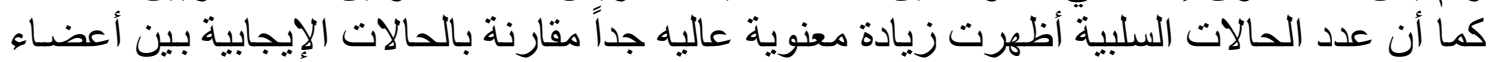

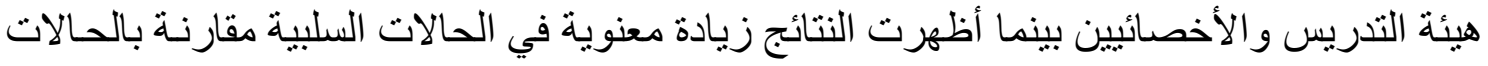

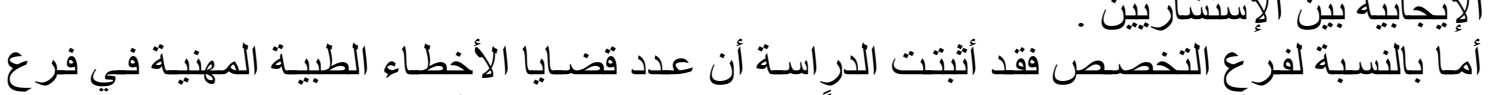

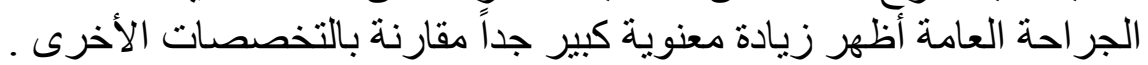

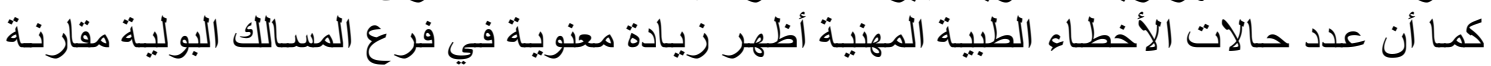

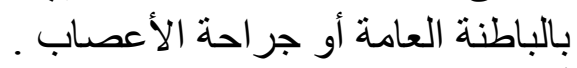
أما بالنسبة للمرحلة التى يحدث فيها النها الخطأ الطبي فقد ثبين وجود زيـادة معنويـة احصـائية كبيرة جداً

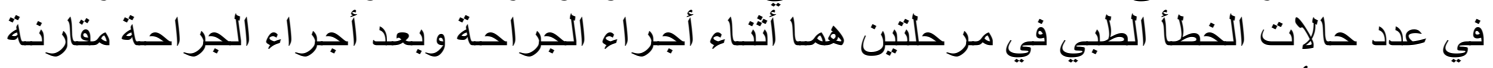

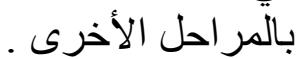

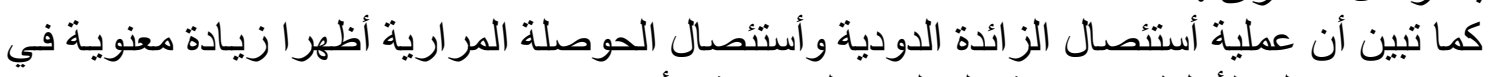

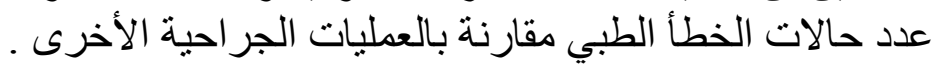

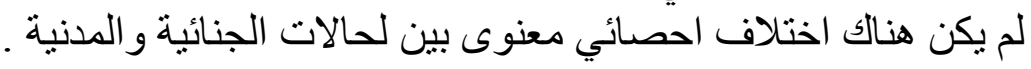


وقد أظهرت هذه الدراسة عدم وجود اختلاف معنوى في عدد الحالات التى كانت نهايتها الثفاء التام

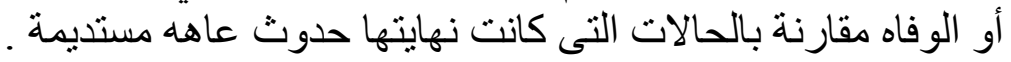

